\title{
A Fuzzy MCDM Approach to Evaluate Green Suppliers
}

\author{
Gizem Çifçi \\ Department of Industrial Engineering, Galatasaray University, Çırağan Caddesi No: 36 \\ Ortaköy, Istanbul, 34357, Turkey \\ E-mail: gizem.cifci@gmail.com \\ Gülçin Büyüközkan ${ }^{1}$ \\ Department of Industrial Engineering, Galatasaray University, Çırağan Caddesi No: 36 \\ Ortaköy, İstanbul, 34357, Turkey \\ E-mail: gulcin.buyukozkan@gmail.com \\ Received 9 April 2010 \\ Accepted 4 April 2011
}

\begin{abstract}
Nowadays the effect of industrial production on the environment brought out the importance of the green concept in supply chains. Particularly for supplier firms, greening is essential in a supply chain because with growing worldwide awareness of environmental protection, green production has become an important theme for almost every manufacturer. While literature related to supplier evaluation is plentiful, the works on green supplier evaluation are rather limited. Therefore, a green supplier evaluation model is proposed in this study. Due to its multi criteria nature, the green supplier evaluation process requires an appropriate multi criteria analysis and solution approach. Selecting a proper method involves an insight analysis among available multi-criteria decision making (MCDM) techniques. Among numerous methods of MCDM, this paper presents a decision framework based on group decision making (GDM) and fuzzy analytic hierarchy process (FAHP) for evaluating and selecting green suppliers. The applicability of the proposed approach is verified through a case study.
\end{abstract}

Keywords: Environmental protection, green suppliers, group decision making, analytic hierarchy process, fuzzy sets.

\section{Introduction}

Industrial production can have crucial effects and damages on the sustainability of the natural environment and human life such as the impacts include depletive resource use, global environmental impacts, local environmental impacts, health impacts, and safety risks. These issues have received more and more attention in recent years and supply chain operation with environmental consideration has become an increasingly important issue. However, in order to improve their relations with the environment, these organizations must contribute towards a reduction in environmental impacts from their supply chains, stimulating improvements in their suppliers' environmental performance. ${ }^{1-5}$ Therefore, these growing interest and importance to the supply function raise the importance of the environmental performance of suppliers. ${ }^{6,7}$ As the public awareness increases, buyers today are learning to purchase goods/services

1

Corresponding Author. Phone: +90 212227 4480; Fax: +90 2122595557.

Published by Atlantis Press

Copyright: the authors 
from suppliers that can provide them with low cost, high quality, short lead time, and at the same time with environmental responsibility. ${ }^{8}$

The most common green supply chain management (SCM) practices involve organizations assessing the environmental performance of their suppliers, requiring suppliers to undertake measures that ensure environmental quality of their products, and evaluating the cost of waste in their operating systems. ${ }^{5}$ In order to obtain the greatest benefits from environmental management, firms must integrate all members in the green supply chain. A high level of environmental performance achieved by a firm may be broken down by a poor level of environmental management by its suppliers. Therefore, green suppliers and their selection, evaluation, etc. processes are vital in a green supply chain.

According to Jabbour and Jabbour, ${ }^{1}$ supplier participation in providing direct inputs for manufacturing companies has intensified recently. Additionally, many studies indicate that suppliers play strategic roles in organizations; they play a vital role in creating a competitive advantage and their actions have a positive impact on the organization's performance. In this sense, supplier selection, and most especially, the establishment of supplier evaluation criteria have been structured at the companies. Once suppliers become responsible for the parts, subsystems etc. of the final product, they incorporate production costs, technological development and quality performance in them, which is why they are important and selected according to operational and strategic factors. With the use of selection criteria that are compatible with the company's competitive strategy, it is possible to achieve an alignment between the two in terms of goals and objectives. As a consequence, if companies want to gain successful and sustainable performance in their green supply chains, selection of appropriate suppliers becomes one of the most fundamental and challenging process for them. ${ }^{8}$

There are various mathematical techniques in literature for supplier evaluation process, such as data envelopment analysis 5 , analytic hierarchy process (AHP), ${ }^{1} \quad$ fuzzy $\quad$ AHP (FAHP), ${ }^{9} \quad$ fuzzy goal programming $^{10}$ and fuzzy analytic network process. ${ }^{11}$ For green supplier selection process, it is required to generate and evaluate alternatives comparing their advantages and disadvantages. Since the evaluation is resulted from the different evaluator's view of linguistic variables, its evaluation must also be conducted in an uncertain, fuzzy environment. Here, $\mathrm{AHP}^{12}$ which is a widely used multiple criteria decision making (MCDM) method offers the opportunity to tackle the complexity of the decision problem by means of a hierarchy of decision layers. The model enables decision makers to divide a decision into smaller parts, starting from the level of goal formulation into criteria down to the level of alternative control actions. Yet for human being's subjective judgment, a theory needed in measuring the ambiguity of these concepts. Because of the vagueness and uncertainty on judgments of the decision maker, the crisp pairwise comparison in the conventional AHP seems to be insufficient and imprecise to capture the correct judgments of decision-maker(s). Fuzzy logic ${ }^{13}$ can be introduced in the pairwise comparison of the AHP to make up for this deficiency in the conventional AHP, referred to as a FAHP. This study includes FAHP methodology to strengthen the comprehensiveness and reasonableness of the green supplier evaluation process. The presence of multiple criteria and the involvement of multiple evaluators will expand the decision space from one to many dimensions, thus the complexity of the decision process will increase. Multiple evaluators are also preferred rather than a single evaluator ${ }^{14,15}$ to avoid the bias and to minimize the partiality in the decision process ${ }^{16}$. Therefore, FAHP is based on group decision making (GDM) process in this study.

The organization of the paper is then as follows. The suggested evaluation model is described in the next section. Following this, the FAHP methodology is briefly presented. The latter section includes the illustration of the proposed evaluation framework through a case study. Finally, some concluding remarks are given in the last section.

\section{2. $\quad$ Proposed Green Supplier Evaluation Model}

Green supply chain management has emerged as a way for firms to achieve profit and market share objectives by lowering environmental impacts and increasing 
ecological efficiency. The benefits to the firm arising from advanced environmental management practice can include: cost reduction (efficient use of raw materials, reduction in fines, risks or insurance costs); quality improvement; early adoption of new regulations; and better human resource management practice. ${ }^{8,17}$ For this reason, a common theme in the supply chain management literature is that green management structure increases the supplier's performance level and supplier selection with green criteria is important for a superior green supply chain. ${ }^{1,5,6,8,18-20}$

In order to develop a rational framework from many different types of environmental criteria, relevant studies in the green supply chain literature are examined. Rao and $\mathrm{Holt}^{21}$ proposed that change for more environmentally-friendly transportation, cleaner production and technologies, environment friendly raw materials, providing information to consumers on environment-friendly products and/or production methods, taking back packaging and recycling of materials internal to the company are important greening issues. Noci ${ }^{20}$ designed a green vendor rating system for the assessment of a supplier's environmental performance based on four environmental categories, namely, green competencies, current environmental efficiency, suppliers' green image and net life cycle cost. Humpreys, Wong and Chan ${ }^{22}$ identified the environmental criteria which influence a firm's purchasing decision, and categorized the criteria into two groups: quantitative environmental criteria and qualitative environmental criteria. The model's second grouping involves criteria evaluated qualitatively, which are organized in the following categories: Environmental management competencies, environmental image of suppliers, development of products with high environmental performance, environmental management system and environmental competencies $^{22}$. In another survey, $\mathrm{Lu}, \mathrm{Wu}$ and $\mathrm{Kuo}^{23}$ considered environmental criteria as materials, energy use, solid residue, liquid residue and gaseous residue for supplier selection process.

Recently, Hsu and $\mathrm{Hu}^{24}$ applied hazardous substance management to supplier selection using ANP. They determined five main criteria as: procurement management, R\&D management, process management, incoming quality control, and management system. Kuo, Wang and Tien ${ }^{25}$ proposed a study that intends to develop a green supplier selection model which integrates artificial neural network (ANN) and two multi-attribute decision analysis (MADA) methods: data envelopment analysis (DEA) and analytic network process (ANP). They determine six green supplier selection dimensions including quality, cost, delivery, service, environment and corporate social responsibility. Awasthi, Chauhan and Goyal ${ }^{26}$ studied a fuzzy multi criteria approach for evaluating environmental performance of suppliers. Their fuzzy TOPSIS based evaluation criteria were usage of environment friendly technology, environment friendly materials, green market share, partnership with green organizations, management commitment to green practices, adherence to environmental policies, involvement in green projects, staff training, lean process planning, design for environment, environmental certification, and pollution control initiatives.

Based on the studies in traditional and green suppliers, and the contribution of industrial experts who actually work in the environmental management and purchasing management related departments of three international companies' Turkish branches; the most important factors for evaluating green suppliers in the literature can be structured in four main criteria as product cost $(\mathrm{C} 1)$, product quality (C2), service performance (C3) and environmental performance (C4). Structure of the evaluation model containing main and sub-criteria is given in the Figure 1.

- Product price $(C 11)^{9,25-29}$ : The firm always requires the minimum price of the product to increase the profitability. The processing cost, maintenance cost, warranty cost, and other costs related to the manufacturing of the product determine the total price of the product.

- Freight cost (C12) ${ }^{30,31}$ : This contains the lengthy distribution channel cost, transport expenses, inventory cost, handling and packaging cost, damages during transportation, and insurance costs.

- Tariff and custom duties $(C 13)^{32-34}$ : Different countries have different norms of imposing tariff and custom duties on the goods and services purchased. Preferences should be given to the supplier country having less duties and taxes.

- Rejection rate of the product $(C 21)^{28,35-37}$ : It is defined in the terms of the number of parts rejected by the customers because of some quality problems and includes the defective parts detected in the incoming quality control and the production line.

- Increased lead time $(C 22)^{28,38}$ : Defective parts, which are not detected in quality control process but noticed afterwards, can increase the lead time of production. 


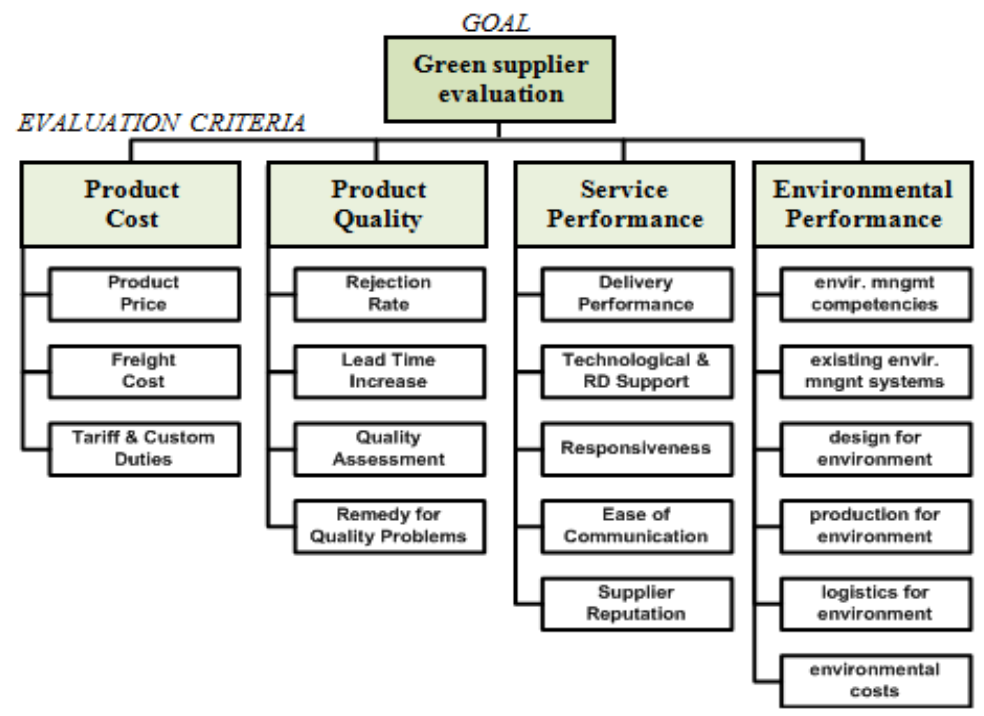

Fig. 1. Proposed green supplier evaluation model

- Quality assessment (C23) $)^{9,19,24,25,28}$ : Includes issues like whether or not the frequent quality assessment of the parts has been done by the supplier. Are suppliers certified for strict quality assurance and do they have a strong commitment for preventing quality failures?

- Remedy for quality problems (C24) ${ }^{19,39,40}$ : This attribute helps in investigating the supplier's ability to solve the quality problems detected by the manufacturer. The capability of the supplier in handling abnormal quality problems is important.

- Delivery performance $(C 31)^{10,19,28,36,42}$ : The ability of the supplier to follow the predefined delivery schedule is always an important criterion for the selection. The manufacturer should access the complete supply chain network on time and have the ability to follow the exact delivery schedule according to the customer's demand.

- Technology and RD support (C32) ${ }^{10,19,24,26}$ : Technology is advancing very fast and suppliers are more likely to assume greater responsibility for outsourced design, engineering service, prototype development and research to increase the performance of the products.

- Responsiveness $(C 33)^{25,28,34,39}$ : The ability of the supplier to change according to the customer's demand, price structure, order frequency and current business scenario has an important impact. A more flexible supplier in terms of the demand constraints can be chosen for better performance towards customer.

- Ease of communication $(C 34)^{10,34,42}$ : The ease of communication and negotiability with the suppliers determine the long-term relation between the supplier and manufacturer. A manufacturing firm should consider attributes such as cultural similarity, ethical standards and electronic data interchange capabilities in order to ensure effective communication.

- Supplier reputation $(C 35)^{10,34,42,43}$ : The performance history of the supplier should be analyzed carefully keeping in mind its past production schedule, response to market, and its ability to make commercial relations and business references. Suppliers with good customer base should be preferred.

- Environmental management competencies $(C 41)^{19,20,28}$ : It is characterized by the supplier's capacity to reduce pollution continuously and to design components that have a low impact on the state of natural resources and are consistent with the company's requirements. The supplier 
organization should be capable of environmental management competencies, so environmental image.

- Existing environmental management systems $(C 42)^{6,19,20,24,28}$ : This should include checking a supplier's environmental policies, implementation and certification of ISO 14001. This process is one of the important factors for suppliers to maintain their sustainability.

- Design for environment (C43) $20,21,24,28,44$ : It includes checking the supplier's design for environment capability (e.g. design for disassembly) so that the product becomes more environmental friendly. The ability of supplier in improving product design in order to reduce the impact on nature is important.

- Production for environment (C44) $)^{6,19,21}$ : It covers the supplier's manufacturing processes and the following factors are significant from an environment perspective: types of energy that are used, low energy production by taking energy saving measures, level at which the company releases materials dangerous to the environment, the extent a supplier is working to improve the immediate environs, and extent the supplier is using dangerous products in its production.

- Logistics for environment $(C 45)^{10,11,19,21,42}$ : Logistics is part of the total life-cycle of a product and therefore what degree the supplier has taken steps to develop and use more environmentfriendly logistics systems is important. The aspects which are included are: return loads, choice of transportation, load optimizing, and the supplier's geographical location.

- Environmental costs $(C 46)^{19,45}$ : Costs due to treatment of pollutants such as costs for solid waste disposal and costs related to improving suppliers environmental performance such as the cost for buying new equipment that will produce less pollutant.

\section{Proposed Analytic Approach: Group Decision Making based Fuzzy AHP Method}

Problems treated within MCDM framework usually involve multiple conflicting criteria. Such problems require comparisons of alternative solutions on the basis of criteria and usually include implicit or explicit trade-offs between the criteria. ${ }^{46}$
The $\mathrm{AHP}^{12}$, first developed by T.L. Saaty in 1980 , is a quantitative technique that facilitates structuring a complex multi-attribute problem, and provides an objective methodology for deciding among a set of solution strategies for solving that problem. AHP has several advantages, including its acceptance of inconsistencies in managerial judgments/perceptions and its user friendliness because users may directly input judgment data without further requiring mathematical knowledge. It also allows users to structure complex problems in the form of a hierarchy or a set of integrated levels. AHP can also be combined with well-known operations research techniques to handle more difficult problems. ${ }^{47}$ But on the other hand, AHP is inadequate and defective in handling the ambiguity of the concepts that are associated with human being's subjective judgments. The FAHP method, which combines AHP and fuzzy logic, allows a more accurate description of the decision making process. Fuzzy set theory is a mathematical theory pioneered by Zadeh, ${ }^{13}$ which is designed to model the vagueness or imprecision of human cognitive processes. The key idea of fuzzy set theory is that an element has a degree of membership in a fuzzy set. ${ }^{57,58}$ A fuzzy set is indicated by a membership function that includes all the information about a fuzzy set. The fuzzy set theory corresponds human reasoning with the usage of approximate information and uncertainty to generate decisions. It has the advantage of mathematically represent uncertainty and ambiguity and provide formalized tools for dealing with the imprecision intrinsic to many problems. For this reason some researchers particularly used the fuzzy extension of AHP for supplier evaluation. As a matter of fact in literature, green supplier evaluation studies can be seen with fuzzy AHP approach. $\mathrm{Lu}, \mathrm{Wu}$ and $\mathrm{Kuo}^{23}$ constructed a multi-objective decision making process for green supply chain management to help managers in measuring and evaluating suppliers' performance using fuzzy AHP method. Recently Lee, Kang, Hsu and Hung $^{19}$ also proposed a green supplier selection model for high-tech industry using fuzzy AHP methodology.

In practice, multiple decision makers (DMs) are preferred rather than single DM. This is mainly because of the 'danger' of relying on a single DM with his/her limitations of experiences, preferences or biases about 
the issues involved. GDM consists of multiple individuals interacting to reach a decision. Each DM or expert may have unique motivations or goals and may approach the decision process from a different angle, but have a common interest in reaching eventual agreement on selecting the "best" option(s). ${ }^{47-49}$ To do this, experts have to express their preferences by means of a set of evaluations over a set of alternatives.

GDM is preferred by several authors. Lu, Zhang, and $\mathrm{Wu}^{50}$ presented a web-based fuzzy group decision support system (WFGDSS) for situation awareness. A fuzzy multi criteria group decision aggregation method was proposed, which uses general fuzzy numbers to present three sets of linguistic terms for identified three uncertain factors: DMs' importance, criteria' importance, and alternatives' importance. Then a consensus group decision was obtained.

$\mathrm{Li}$, Ruan, Liu, and $\mathrm{Xu}^{51}$ proposed a linguisticvalued weighted aggregation operator to multiple attribute GDM with quantitative and qualitative information. They used a lattice-based linguistic-valued weighted aggregation (LVWA) operator is for GDM process with non-totally ordered linguistic-valued information.

Wei, Zhao, and $\operatorname{Lin}^{52}$ studied some induced aggregating operators with fuzzy number intuitionistic fuzzy information and their applications to GDM. In their study, induced fuzzy number intuitionistic fuzzy ordered weighted geometric (I-FIFOWG) operator and fuzzy number intuitionistic fuzzy weighted geometric (FIFWG) operator based approach is developed to solve the multiple attiribute GDM under the fuzzy number intuitionistic fuzzy environment. GDM is also used with AHP methodology in many studies. ${ }^{53-55}$

Fig. 2 briefly illustrates the proposed methodology.

Step 1: After setting the decision goal, construct a committee of experts with $E$ members and determine the alternatives and sets of criteria for evaluation.

Step 2: Design the fuzzy linguistic scale and develop the criteria evaluation. In this step, determination of relative importance among the attributes using experts' opinion through paired comparison analysis is needed. Firstly, for the purpose of measuring the relationship between criteria, it is

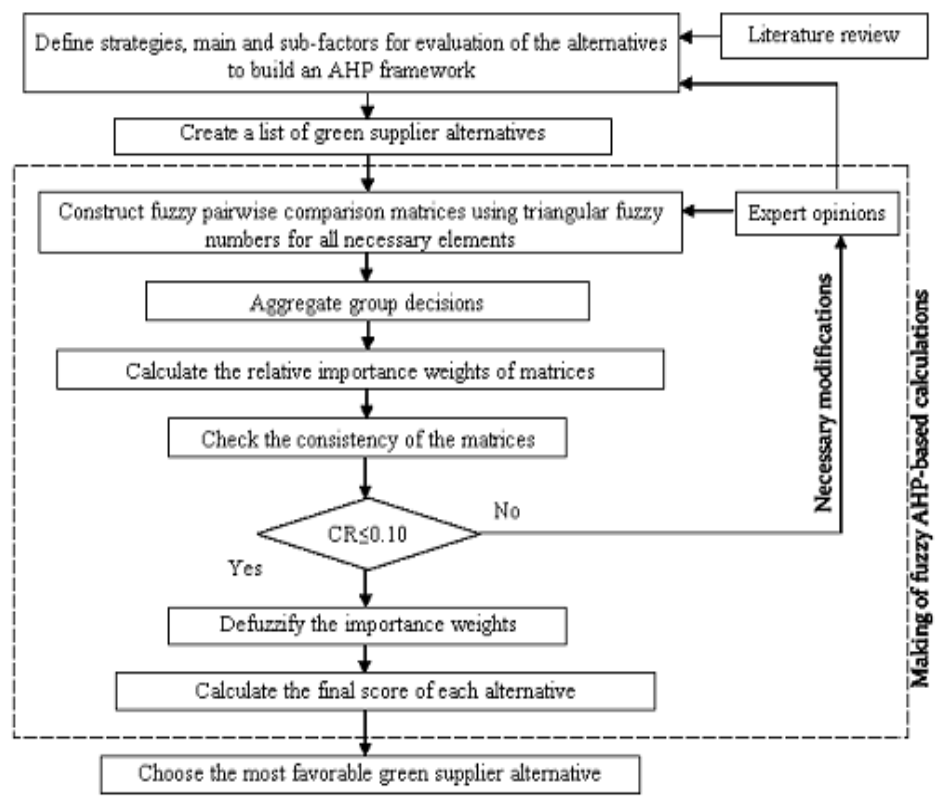

Fig. 2. Proposed evaluation methodology

Published by Atlantis Press

Copyright: the authors 
required to design the comparison scale as shown in Table 1.

Table 1. Linguistic variables for rating criteria importance

\begin{tabular}{ccc}
\hline $\begin{array}{c}\text { Linguistic } \\
\text { term }\end{array}$ & Abbrv. & $\begin{array}{c}\text { Fuzzy Membership } \\
\text { Function }\end{array}$ \\
\hline None & $\mathrm{N}$ & $(0,0,0.1)$ \\
Very Low & VL & $(0,0.1,0.2)$ \\
Low & $\mathrm{L}$ & $(0.1,0.2,0.3)$ \\
Fairly Low & FL & $(0.2,0.3,0.4)$ \\
More or less Low & ML & $(0.3,0.4,0.5)$ \\
Medium & $\mathrm{M}$ & $(0.4,0.5,0.6)$ \\
More or less Good & MG & $(0.5,0.6,0.7)$ \\
Fairly Good & FG & $(0.6,0.7,0.8)$ \\
Good & $\mathrm{G}$ & $(0.7,0.8,0.9)$ \\
Very Good & VG & $(0.8,0.9,1)$ \\
Excellent & $\mathrm{E}$ & $(0.9,1,1)$ \\
\hline
\end{tabular}

Step 3: Construct the fuzzy comparison matrices. Triangular fuzzy numbers are used to indicate the relative strength of each pair of elements and to the preferences of the decision maker in the same hierarchy. By using triangular fuzzy numbers, via pairwise comparison, the fuzzy judgment matrix $\widetilde{A}$ is constructed as given below:

$$
\widetilde{A}=\left[\begin{array}{cccc}
\tilde{a}_{11} & \tilde{a}_{12} & \ldots & \widetilde{a}_{1 n} \\
\tilde{a}_{21} & \tilde{a}_{22} & \ldots & \tilde{a}_{2 n} \\
\cdot & & & \cdot \\
\cdot & & & \cdot \\
\cdot & & & \cdot \\
\tilde{a}_{n 1} & \tilde{a}_{n 2} & \ldots & \tilde{a}_{n n}
\end{array}\right]
$$

where $\tilde{a}_{i j}=\left(a_{i j}^{l}, a_{i j}^{m}, a_{i j}^{u}\right)$ indicates the importance among the compared criteria (importance of $\mathrm{i}$ over $\mathrm{j}$ ) where $i=j=1,2, \ldots, \mathrm{n}$.

Step 4: Aggregate the group decision. As group members play different roles in an organization, the relative importance of DMs may not be equal in the decision group. Some can be more important than the others. Therefore, the relative importance weighting of each DM should be considered. The normalized weight $v_{k}$ of an expert $E_{k}(k=1, \ldots, p)$ is denoted as

$$
v_{k}^{*}=v_{k} / \sum_{i=1}^{n} v_{i} \text {. }
$$

Considering the weights of all decision makers in the group, a weighted normalized fuzzy decision matrix $A$ can be constructed,

$$
\left[\begin{array}{cccc}
\widetilde{a}_{11} & \tilde{a}_{12} & \ldots & \tilde{a}_{1 n} \\
\widetilde{a}_{21} & \tilde{a}_{22} & \ldots & \widetilde{a}_{2 n} \\
\cdot & & & \cdot \\
\cdot & & & \cdot \\
\cdot & & & \cdot \\
\tilde{a}_{n 1} & \tilde{a}_{n 2} & \ldots & \tilde{a}_{n n}
\end{array}\right]=\sum_{i=1}^{p} v_{k}^{*}\left[\begin{array}{cccc}
\tilde{a}_{11}^{k} & \tilde{a}_{12}^{k} & \ldots & \tilde{a}_{1 n}^{k} \\
\tilde{a}_{21}^{k} & \tilde{a}_{22}^{k} & \ldots & \tilde{a}_{2 n}^{k} \\
\cdot & & & \cdot \\
\cdot & & & \cdot \\
\cdot & & & \cdot \\
\tilde{a}_{n 1}^{k} & \tilde{a}_{n 2}^{k} & \ldots & \tilde{a}_{n n}^{k}
\end{array}\right]
$$

Step 5: Estimate triangular fuzzy priorities $\widetilde{w}_{i}$ where $\mathrm{i}=1,2, \ldots, \mathrm{n}$ from the judgment matrix. The logarithmic least-squares method can be used for calculating these weights ${ }^{56,57}$ :

$$
\begin{array}{r}
\tilde{w}_{k}=\left(w_{k}^{l}, w_{k}^{m}, w_{k}^{u}\right) \mathrm{k}=1,2, \ldots, \mathrm{n} \text { where } \\
w_{k}^{s}=\frac{\left(\prod_{i=1}^{n} a_{k j}^{s}\right)^{1 / n}}{\sum_{i=1}^{n}\left(\prod_{i=1}^{n} a_{i j}^{m}\right)^{1 / n}}, s \in\{l, m, u\}
\end{array}
$$

for $0<\alpha \leq 1$ and all $i, j$, where $i=1,2 \ldots n, j=1,2 \ldots$ . $n$.

In order to control the result of the method, the consistency ratio for each of the matrices and the overall inconsistency for the hierarchy are calculated. The Consistency Ratio (CR) is used to directly estimate the consistency of the pair-wise comparisons as:

$\mathrm{CR}=\mathrm{CI} / \mathrm{RI}$, where $\mathrm{CI}=\frac{\lambda_{\max }-n}{n-1}$.

CR should be less than 0.10 . Then it can be said the comparisons are acceptable, otherwise they are not acceptable and should be revised. In this study, the inconsistency ratios for all the comparison matrices were calculated for the mean values of the fuzzy numbers. Because the lower and upper values provide flexibility for human judgments, they are not expected to have rigid consistency.

Step 6: Defuzzify the weights obtained from fuzzy matrices. In this step, defuzzification of the weights is done by using Eq. (9).

$$
F\left(\widetilde{t}_{i j}\right)=1 / 2 \int_{0}^{l}\left(\inf _{x \in \Re} \widetilde{t}_{i j}^{\alpha}+\sup _{x \in \Re} \widetilde{t}_{i j}^{\alpha}\right) d \alpha
$$


Step 7: Evaluate the alternatives. The priority weight of each alternative can be obtained by multiplying the matrix of evaluation ratings by the vector of attribute weights and summing over all attributes.

\section{Application of the Proposed Approach}

Technological advancements, new competitors, global sourcing and industry restructuring result in great challenges for the automotive industry. According to the growing worldwide environmental awareness, improvements in this industry also need to shift from a focus on improvements in product environmental performance. Automotive industry has a vital importance for the economy of Turkey and particularly the international companies, which manufacture in Turkey, attach great importance to environmental concerns. Correspondingly, Turkish companies manufacture not only for Turkey but also for worldwide; and either regard environmental standards, laws, and regulations, most especially European Union (EU).

The automotive industry is characterized by a high degree of value added by suppliers in manufacturing as well as in the engineering of automotive components which strongly suggests the implementation of collaborative approaches. ${ }^{58}$ From now on, environmental performance of suppliers is a very important concern. Turkish automotive companies are also pioneers in green supply chain management and green supplier issues in Turkish industry. Therefore, a case study research is conducted in XYZ Company, (The name is not given due to privacy concerns.) a main producer of Turkish automotive industry in order to examine the proposed green supplier evaluation model.

Three XYZ managers are the experts, so DMs, of our study. DM1 is purchasing manager, DM2 is environment and quality systems manager, and DM3 is executive vice president responsible for production.
$\mathrm{XYZ}$ Company's green supplier evaluation process is then performed as follows.

The first step is determination of evaluation criteria and alternatives. The DMs confirm the determined evaluation criteria that have been discussed in the previous section. Five green supplier alternatives (A1,A2,A3,A4,A5) are identified by these DMs of the XYZ company. Supplier alternatives are characterized as small medium enterprises (SMEs). They manufacture not only for Turkish companies but also for international automotive companies. Thus, they have further environmental based concerns and applications rather than other suppliers. The next step comes with the design of the fuzzy linguistic scale which was mentioned in Table 1. Afterwards, the construction of fuzzy comparison matrices for evaluation is realized. DMs make sets of comparisons in terms of relation between main and sub-criteria. Linguistic evaluation matrices of DMs are given in the Tables 2-16.

Different degrees of relations are expressed among experts for criteria evaluation; thereby aggregation of the experts' opinions is made by applying Eqs. (2) and (3). The relative importance degrees of the three DMs are $0.40,0.30$ and 0.30 respectively. The aggregation matrices are in Tables 17-21.

Sub-criteria evaluations are performed in the same way. After all the fuzzy pairwise comparison matrices are constructed by using fuzzy scale, priorities are obtained by applying Eq. (4). After the defuzzification step with using Eq. (6), the obtaining final criteria weights are given in Table 22 .

After main and sub-criteria evaluations, alternative evaluations for every sub-criterion should be performed. Aggregation of the experts' opinions for evaluation of the alternatives is made with Eqs. (2) and (3); priorities are obtained by Eq. (4) and defuzzified by Eq. (6) again. The consistency ratios of all the pairwise comparison matrices were less than 0.1 , thereby all comparison matrices were assumed to be consistent and the judgments were considered reliable. 
Table 2. Linguistic evaluation matrix of DM1 for main criteria

\begin{tabular}{ccccc}
\hline & C1 & C2 & C3 & C4 \\
\hline Product Cost (C1) & 1 & FG & VG & FG \\
Product Quality (C2) & & 1 & VG & VG \\
Service Perform. (C3) & & & 1 & VG \\
Environmental Perform. (C4) & & & & 1 \\
\hline
\end{tabular}

Table 3. Linguistic evaluation matrix of DM2 for main criteria

\begin{tabular}{ccccc}
\hline & $\mathrm{C} 1$ & $\mathrm{C} 2$ & $\mathrm{C} 3$ & $\mathrm{C} 4$ \\
\hline $\mathrm{C} 1$ & 1 & $\mathrm{VG}$ & $\mathrm{VG}$ & $\mathrm{FG}$ \\
$\mathrm{C} 2$ & & 1 & $\mathrm{VG}$ & $\mathrm{VG}$ \\
$\mathrm{C} 3$ & & & 1 & $\mathrm{VG}$ \\
$\mathrm{C} 4$ & & & & 1 \\
\hline
\end{tabular}

Table 4. Linguistic evaluation matrix of DM3 for main criteria

\begin{tabular}{ccccc}
\hline & $\mathrm{C} 1$ & $\mathrm{C} 2$ & $\mathrm{C} 3$ & $\mathrm{C} 4$ \\
\hline $\mathrm{C} 1$ & 1 & $\mathrm{FG}$ & $\mathrm{VG}$ & $\mathrm{G}$ \\
$\mathrm{C} 2$ & & 1 & $\mathrm{VG}$ & $\mathrm{G}$ \\
$\mathrm{C} 3$ & & & 1 & $\mathrm{G}$ \\
$\mathrm{C} 4$ & & & & 1 \\
\hline
\end{tabular}

Table 5. Linguistic evaluation matrix of DM1 for $\mathrm{C} 1$ sub-criteria

\begin{tabular}{cccc}
\hline Product Cost (C1) & C11 & C12 & C13 \\
\hline Product Price (C11) & 1 & & \\
Freight Cost (C12) & M & 1 & \\
Tariff and Custom Duties (C13) & FL & FL & 1 \\
\hline
\end{tabular}

Table 6. Linguistic evaluation matrix of DM2 for $\mathrm{C} 1$ sub-criteria

\begin{tabular}{cccc}
\hline $\mathrm{C} 1$ & $\mathrm{C} 11$ & $\mathrm{C} 12$ & $\mathrm{C} 13$ \\
\hline $\mathrm{C} 11$ & 1 & & \\
$\mathrm{C} 12$ & $\mathrm{ML}$ & 1 & \\
$\mathrm{C} 13$ & $\mathrm{ML}$ & $\mathrm{ML}$ & 1 \\
\hline
\end{tabular}

Table 7. Linguistic evaluation matrix of DM3 for $\mathrm{C} 1$ sub-criteria

\begin{tabular}{cccc}
\hline $\mathrm{C} 1$ & $\mathrm{C} 11$ & $\mathrm{C} 12$ & $\mathrm{C} 13$ \\
\hline $\mathrm{C} 11$ & 1 & & \\
$\mathrm{C} 12$ & $\mathrm{M}$ & 1 & \\
$\mathrm{C} 13$ & $\mathrm{FL}$ & FL & 1 \\
\hline
\end{tabular}


Table 8. Linguistic evaluation matrix of DM1 for $\mathrm{C} 2$ sub-criteria

\begin{tabular}{ccccc}
\hline Product Quality (C2) & C21 & C22 & C23 & C24 \\
\hline Rejection Rate (C21) & 1 & & E & \\
Lead Time Increase (C22) & FL & 1 & E & \\
Quality Assessment (C23) & & & 1 & E \\
Remedy for Quality Prob. (C24) & FL & FG & & 1 \\
\hline
\end{tabular}

Table 9. Linguistic evaluation matrix of DM2 for $\mathrm{C} 2$ sub-criteria

\begin{tabular}{ccccc}
\hline $\mathrm{C} 2$ & $\mathrm{C} 21$ & $\mathrm{C} 22$ & $\mathrm{C} 23$ & $\mathrm{C} 24$ \\
\hline $\mathrm{C} 21$ & 1 & & & \\
$\mathrm{C} 22$ & $\mathrm{M}$ & 1 & $\mathrm{VG}$ & \\
$\mathrm{C} 23$ & $\mathrm{G}$ & & 1 & $\mathrm{E}$ \\
$\mathrm{C} 24$ & $\mathrm{FL}$ & $\mathrm{VG}$ & & 1 \\
\hline
\end{tabular}

Table 10. Linguistic evaluation matrix of DM3 for $\mathrm{C} 2$ sub-criteria

\begin{tabular}{ccccc}
\hline $\mathrm{C} 2$ & $\mathrm{C} 21$ & $\mathrm{C} 22$ & $\mathrm{C} 23$ & $\mathrm{C} 24$ \\
\hline $\mathrm{C} 21$ & 1 & & & 1 \\
$\mathrm{C} 22$ & $\mathrm{M}$ & 1 & $\mathrm{G}$ & $\mathrm{M}$ \\
$\mathrm{C} 23$ & $\mathrm{MG}$ & & 1 & $\mathrm{MG}$ \\
$\mathrm{C} 24$ & $\mathrm{FL}$ & $\mathrm{G}$ & $\mathrm{FG}$ & $\mathrm{FL}$ \\
\hline
\end{tabular}

Table 11. Linguistic evaluation matrix of DM1 for $\mathrm{C} 3$ sub-criteria

\begin{tabular}{cccccc}
\hline Service Performance (C3) & C31 & C32 & C33 & C34 & C35 \\
\hline Delivery Performance (C31) & 1 & & & & \\
Technical \& RD Support (C32) & MG & 1 & E & E & E \\
Responsiveness (C33) & FG & & 1 & & E \\
Ease of communication (C34) & FL & & FG & 1 & FL \\
Supplier Reputation (C35) & FL & & & & 1 \\
\hline
\end{tabular}

Table 12. Linguistic evaluation matrix of DM2 for $\mathrm{C} 3$ sub-criteria

\begin{tabular}{cccccc}
\hline C3 & C31 & C32 & C33 & C34 & C35 \\
\hline C31 & 1 & & & & \\
C32 & M & 1 & VG & & VG \\
C33 & FG & & 1 & E & \\
C34 & L & G & & 1 & MG \\
C35 & FG & & FG & & 1 \\
\hline
\end{tabular}


Table 13. Linguistic evaluation matrix of DM3 for $\mathrm{C} 3$ sub-criteria

\begin{tabular}{cccccc}
\hline $\mathrm{C} 3$ & $\mathrm{C} 31$ & $\mathrm{C} 32$ & $\mathrm{C} 33$ & $\mathrm{C} 34$ & $\mathrm{C} 35$ \\
\hline $\mathrm{C} 31$ & 1 & & & & \\
$\mathrm{C} 32$ & $\mathrm{M}$ & 1 & $\mathrm{E}$ & & $\mathrm{VG}$ \\
$\mathrm{C} 33$ & $\mathrm{FG}$ & & 1 & & $\mathrm{E}$ \\
$\mathrm{C} 34$ & $\mathrm{~L}$ & $\mathrm{VG}$ & $\mathrm{FG}$ & 1 & $\mathrm{G}$ \\
$\mathrm{C} 35$ & $\mathrm{FG}$ & & & & 1 \\
\hline
\end{tabular}

Table 14. Linguistic evaluation matrix of DM1 for C4 sub-criteria

\begin{tabular}{ccccccc}
\hline Environmental Performance (C4) & C41 & C42 & C43 & C44 & C45 & C46 \\
\hline Env. Mngmnt. Competencies (C41) & 1 & E & & E & & \\
Existing env. mngmnt. Systems (C42) & & 1 & E & E & & \\
Design for environment (C43) & VG & & 1 & E & E & \\
Production for environment (C44) & & & & 1 & & \\
Logistics for environment (C45) & FL & FL & & M & 1 & E \\
Environmental costs (C46) & FL & FG & M & ML & & 1 \\
\hline
\end{tabular}

Table 15. Linguistic evaluation matrix of DM2 for $\mathrm{C} 4$ sub-criteria

\begin{tabular}{ccccccc}
\hline C4 & C41 & C42 & C43 & C44 & C45 & C46 \\
\hline C41 & 1 & & & & & \\
C42 & VG & 1 & E & E & & \\
C43 & G & & 1 & VG & & \\
C44 & VG & & & 1 & & \\
C45 & ML & M & FG & M & 1 & E \\
C46 & ML & M & FG & M & & 1 \\
\hline
\end{tabular}

Table 16. Linguistic evaluation matrix of DM3 for $\mathrm{C} 4$ sub-criteria

\begin{tabular}{ccccccc}
\hline C4 & C41 & C42 & C43 & C44 & C45 & C46 \\
\hline C41 & 1 & E & & & & \\
C42 & & 1 & E & E & & \\
C43 & G & & 1 & E & & \\
C44 & VG & & & 1 & & \\
C45 & ML & M & FG & M & 1 & E \\
C46 & ML & M & FG & M & & 1 \\
\hline
\end{tabular}

Table 17. Fuzzy aggregated evaluation matrix main criteria

\begin{tabular}{ccccc}
\hline & $\mathrm{C} 1$ & $\mathrm{C} 2$ & $\mathrm{C} 3$ & $\mathrm{C} 4$ \\
\hline $\mathrm{C} 1$ & 1 & $(0.66,0.76,0.86)$ & $(0.8,0.9,1)$ & $(0.63,0.73,0.83)$ \\
$\mathrm{C} 2$ & $(1 / 0.86,1 / 0.76,1 / 0.66)$ & 1 & $(0.8,0.9,1)$ & $(0.77,0.87,0.97)$ \\
$\mathrm{C} 3$ & $(1 / 1,1 / 0.9,1 / 0.8)$ & $(1 / 1,1 / 0.9,1 / 0.8)$ & 1 & $(0.77,0.87,0.97)$ \\
$\mathrm{C} 4$ & $(1 / 0.83,1 / 0.73,1 / 0.63)$ & $(1 / 0.97,1 / 0.87,1 / 0.77)$ & $(1 / 0.97,1 / 0.87,1 / 0.77)$ & 1 \\
\hline
\end{tabular}


Table 18. Fuzzy aggregated evaluation matrix $\mathrm{C} 1$ sub-criteria

\begin{tabular}{cccc}
\hline & $\mathrm{C} 11$ & $\mathrm{C} 12$ & $\mathrm{C} 13$ \\
\hline $\mathrm{C} 11$ & 1 & $(1.76,2.15,2.75)$ & $(2.35,3.08,4.5)$ \\
$\mathrm{C} 12$ & $(1 / 2.75,1 / 2.15,1 / 1.76)$ & 1 & $(2.35,3.08,4.5)$ \\
$\mathrm{C} 13$ & $(1 / 4.5,1 / 3.08,1 / 2.35)$ & $(1 / 4.5,1 / 3.08,1 / 2.35)$ & 1 \\
\hline
\end{tabular}

Table 19. Fuzzy aggregated evaluation matrix C2 sub-criteria

\begin{tabular}{ccccc}
\hline & $\mathrm{C} 21$ & $\mathrm{C} 22$ & $\mathrm{C} 23$ & $\mathrm{C} 24$ \\
\hline C21 & 1 & $(2,2.53,3.5)$ & $(1.12,1.27,1.42)$ & $(2.5,3.33,5)$ \\
C22 & $(1 / 3.5,1 / 2.53,1 / 0.2)$ & 1 & $(0.81,0.91,0.97)$ & $(1.13,1.27,1.47)$ \\
C23 & $(1 / 1.42,1 / 1.27,1 / 1.42)$ & $(1 / 0.97,1 / 0.91,1 / 0.81)$ & 1 & $(1,1.12,1.2)$ \\
C24 & $(1 / 5,1 / 3.33,1 / 2.5)$ & $(1 / 1.47,1 / 1.27,1 / 1.13)$ & $(1 / 1.2,1 / 1.12,1 / 1)$ & 1 \\
\hline
\end{tabular}

Table 20. Fuzzy aggregated evaluation matrix C3 sub-criteria

\begin{tabular}{cccccc}
\hline & C31 & C32 & C33 & C34 & C35 \\
\hline C31 & 1 & $(1.57,1.86,2.3)$ & $(1.25,1.42,1.66)$ & $(3,4.33,8)$ & $(1.75,2.19,3)$ \\
C32 & $(1 / 2.3,1 / 1.86,1 / 1.57)$ & 1 & $(1.6,1.78,2.12)$ & $(0.99,1.10,1.20)$ & $(0.84,0.94,1)$ \\
C33 & $(1 / 1.66,1 / 1.42,1 / 1.25)$ & $(1 / 2.12,1 / 1.78,1 / 1.6)$ & 1 & $(1.20,1.42,1.76)$ & $(1,1.12,1.20)$ \\
C34 & $(1 / 8,1 / 4.33,1 / 3)$ & $(1 / 1.20,1 / 1.10,1 / 0.99)$ & $(1 / 1.76,1 / 1.42,1 / 1.2)$ & 1 & $(0.44,0.54,0.64)$ \\
C35 & $(1 / 8,1 / 4.33,1 / 3)$ & $(1 / 1,1 / 0.94,1 / 0.84)$ & $(1 / 1.2,1 / 1.12,1 / 1)$ & $(1 / 0.64,1 / 0.54,1 / 0.44)$ & 1 \\
\hline
\end{tabular}

Table 21. Fuzzy aggregated evaluation matrix C4 sub-criteria

\begin{tabular}{ccccccc}
\hline & C41 & C42 & C43 & C44 & C45 & C46 \\
\hline C41 & 1 & $(0.93,1.03,1.07)$ & $(1.06,1.19,1.35)$ & $(0.96,1.06,1.15)$ & $(2.20,2.83,4)$ & $(2.20,2.83,4)$ \\
C42 & & 1 & $(1.63,1.81,2.12)$ & $(0.9,1,1)$ & $(2,2.53,3.5)$ & $(1.5,1.77,2.16)$ \\
C43 & $(1 / 1.07,1 / 1.03,1 / 0.93)$ & $(1 / 2.12,1 / 1.81,1 / 1.63)$ & 1 & $(0.87,0.97,1)$ & $(1.11,1.25,1.4)$ & $(1.41,1.65,2)$ \\
C44 & $(1 / 1.35,1 / 1.19,1 / 1.06)$ & $(1 / 1,1 / 1,1 / 0.9)$ & $(1 / 1,1 / 0.97,1 / 0.87)$ & 1 & $(1.66,2,2.5)$ & $(1.80,2.2,2.83)$ \\
C45 & $(1 / 1.15,1 / 1.06,1 / 0.96)$ & $(1 / 3.5,1 / 2.53,1 / 2.20)$ & $(1 / 1.4,1 / 1.25,1 / 1.11)$ & $(1 / 2.5,1 / 2,1 / 1.66)$ & 1 & $(0.9,1,1)$ \\
C46 & $(1 / 4,1 / 2.83,1 / 2.20)$ & $(1 / 2.16,1 / 1.77,1 / 1.5)$ & $(1 / 2,1 / 1.65,1 / 1.41)$ & $(1 / 2.83,1 / 2,1 / 1.8)$ & $(1 / 1,1 / 1,1 / 0.9)$ & 1 \\
\hline
\end{tabular}

The final ranking obtained from all the fuzzy AHP calculations is given in Table 23. Final results demonstrate that, the second supplier namely A2 fulfills the green supplier goal mostly because of the highest score among alternatives. Therefore it seems like the best option is to select A2.

\section{Conclusion}

Sustainable development and environmental protection are getting more and more attention in industry. A good green supplier selection model in the competitive environment can help lessen the environmental and legal risks and increase the competitiveness of a firm.
For this reason, this paper proposed an evaluation model to determine the criteria for evaluating green suppliers, and to evaluate the performance of suppliers. In general, multi criteria problems adhere to uncertain and imprecise data and fuzzy set theory is adequate to deal with case. Therefore, fuzzy AHP methodology was used in the evaluation process. An empirical case study from Turkish automotive industry was used to exemplify the approach. The strength of the proposed model is that the vagueness of experts' opinions is considered in the evaluation process. Manufacturers of related industries can use this proposed model to meet their own needs, to evaluate their green suppliers and to select the best green supplier. 
Table 22. Main and sub-criteria weights for green supplier selection

\begin{tabular}{lclc}
\hline Main criteria & Priority & Sub-criteria & Priority \\
\hline Product Cost & 0.21 & Product Price & 0.55 \\
& & Freight Cost & 0.32 \\
Product Quality & \multirow{2}{*}{0.25} & Tariff and Custom Duties & 0.13 \\
& & Rejection Rate & 0.42 \\
& & Lead Time Increase & 0.19 \\
& & Quality Assessment & 0.23 \\
Service & \multirow{2}{*}{0.25} & Remedy for Quality Problems & 0.16 \\
Performance & & Delivery Performance & 0.36 \\
& & Technical \& RD Support & 0.18 \\
& & Responsiveness & 0.17 \\
Environmental & & Ease of communication & 0.11 \\
Performance & & Supplier Reputation & 0.18 \\
\cline { 2 - 4 } & \multirow{2}{*}{0.29} & Env. Mngmnt. Competencies & 0.23 \\
& & Existing env. mngmnt. systems & 0.22 \\
& & Design for environment & 0.15 \\
& & Production for environment & 0.20 \\
& & Logistics for environment & 0.10 \\
& & Environmental costs & 0.10 \\
\hline
\end{tabular}

Table 23. Final ranking of the green supplier alternatives

\begin{tabular}{cccccc}
\hline & \multicolumn{4}{c}{ Main Attributes of Goal } & Alternative \\
\cline { 2 - 5 } & $\begin{array}{c}\text { Product } \\
\text { Cost }\end{array}$ & $\begin{array}{c}\text { Product } \\
\text { Quality }\end{array}$ & $\begin{array}{c}\text { Service } \\
\text { Performance }\end{array}$ & $\begin{array}{c}\text { Environmental } \\
\text { Performance }\end{array}$ & $\begin{array}{c}\text { Priority } \\
\text { Weight }\end{array}$ \\
\hline Weight & 0.21 & 0.25 & 0.25 & 0.29 & \\
\hline A1 & 0.1845 & 0.2028 & 0.2129 & 0.2204 & 0.207 \\
A2 & 0.1958 & 0.2338 & 0.2292 & 0.2595 & $\underline{\mathbf{0 . 2 3 2}}$ \\
A3 & 0.2232 & 0.1740 & 0.1751 & 0.1879 & 0.189 \\
A4 & 0.2042 & 0.1865 & 0.1857 & 0.2078 & 0.196 \\
A5 & 0.1923 & 0.2029 & 0.1971 & 0.2244 & 0.205 \\
\hline
\end{tabular}

For further research, the other multi attribute methods like fuzzy TOPSIS ${ }^{59,60}$ can be developed to compare with the results of fuzzy AHP methodology. Another research possibility could be to take into account the criteria dependencies.

\section{Acknowledgements}

The authors would like to express their gratitude to the industrial experts for their support in evaluation of the framework. The authors acknowledge also the financial support of the Galatasaray University Research Fund. 


\section{References}

1. A. B. L. S. Jabbour and C. J. C. Jabbour, Are supplier selection criteria going green? Case studies of companies in Brazil, Industrial Management \& Data Systems 109 (2009) 477-495.

2.G. Svensson, Aspects of sustainable supply chain management (SSCM): conceptual framework and empirical example, Supply Chain Management: An International Journal 12(4) (2007) 262-266.

3.G. Ofori, Greening the construction supply chain in Singapore, European Journal of Purchasing \& Supply Chain Management 6(3-4) (2000) 195-206.

4.G. Kova'cs, Corporate environmental responsibility in the supply chain, Journal of Cleaner Production 16(15) (2008) 1571-1578.

5.R. Handfield, S. Walton, R. Sroufe, and S. Melnyk, Applying environmental criteria to supplier assessment: a study in the application of the analytical hierarchy process, European Journal of Operational Research 141 (2002) 70-87.

6.D. F. Simpson and D. J. Power, Use the supply relationship to develop lean and green suppliers, Supply Chain Management: An International Journal 10 (2005) 60-68.

7.J. Sarkis, A strategic decision framework for green supply chain management, Journal of Cleaner Production 11(4) (2003) 397-409.

8.J. Hall, Environmental supply chain dynamics, Journal of Cleaner Production 8(3) (2000) 455-471.

9.D. Wu, Supplier selection: A hybrid model using DEA, decision tree and neural network, Expert Systems with Applications 36 (2009) 9105-9112.

10. M. Sevkli, S. C. L. Koh, S. Zaim, M. Demirbag, and E. Tatoglu, An application of data envelopment analytic hierarchy process for supplier selection: a case study of BEKO in Turkey, International Journal of Production Research 45 (2007) 1973-2003.

11. F. T. S. Chan, and N. Kumar, Global supplier development considering risk factors using fuzzy extended AHP-based approach, Omega 35 (2007) 417431.

12. T. L. Saaty, The Analytical Hierarchy Process (McGraw-Hill, New York,1980).

13. L. A. Zadeh, Fuzzy set, Information and Control 8 (1965) 338-353.

14. F. Chiclana, F. Herrera, and E. Herrera-Viedma, Integrating three representation models in fuzzy multipurpose decision making based on fuzzy preference relations, Fuzzy Sets and Systems 97 (1998) 33-48.

15. F. Herrera, E. Herrera-Viedma, and F. Chiclana, Multiperson decision-making based on multiplicative preference relations, European Journal of Operational Research 129 (2001) 372-385.
16. J. W. Lee and S. H. Kim, Using analytic network process and goal programming for interdependent information system project selection, Computers \& Operations Research 27 (2000) 367-382.

17. W. -H. Tsai, and S. -J. Hung, A fuzzy goal programming approach for green supply chain optimization under activity-based costing and performance evaluation with a value-chain structure, International Journal of Production Research (2009) 127.

18. F. Bowen, P. Cousins, R. Lamming, and A. Faruk, The role of supply management capabilities in green supply, Production and Operations Management 10(2) (2001) 174-189.

19. A. H. I. Lee, H. -Y. Kang, C. -F. Hsu, and H.-C. Hung, A green supplier selection model for high-tech industry, Expert Systems with Applications 36 (2009) 7917-7927.

20. G. Noci, Designing green vendor rating systems for the assessment of a supplier's environmental performance, European Journal of Purchasing and Supply Management 2 (1997) 103-114.

21. P. Rao and D. Holt, Do green supply chains lead to competitiveness and economic performance?, International Journal of Operations \& Production Management 25 (2005) 898-916.

22. P. K. Humphreys, Y. K. Wong, and F. T. S.Chan, Integrating environmental criteria into the supplier selection process, Journal of Materials Processing Technology 138 (2003) 349-356.

23. L. Y. Y. Lu, C. H. Wu, and T. -C. Kuo, Environmental principles applicable to green supplier evaluation by using multiobjective decision analysis, International Journal of Production Research 45 (2007) 4317-4331.

24. C. -W. Hsu and A. H. Hu, Applying hazardous substance management to supplier selection using analytic network process, Journal of Cleaner Production 17(2) (2009) 255-264.

25. R. J. Kuo, Y. C. Wang, and F. C. Tien, Integration of artificial neural network and MADA methods for green supplier selection, Journal of Cleaner Production 18(12) (2010) 1161-1170 .

26. A. Awasthi, S. S. Chauhan, and S. K. Goyal, A fuzzy multicriteria approach for evaluating environmental performance of suppliers, International Journal of Production Economics 126(2) (2010) 370378.

27. T. N. Gladwin, J. J. Kennelly, T. Krause, Shifting paradigms for sustainable development: implications for management theory and research, Academy of Management Review 20 (1995) 874-907. 
28. S. Matos, J. Hall, Integrating sustainable development in the supply chain: The case of life cycle assessment in oil and gas and agricultural biotechnology, Journal of Operations Management 25 (2007) 10831102.

29. D. Zhang, J. Zhang, K. K. Lai, and Y. Lu, An novel approach to supplier selection based on vague sets group decision, Expert Systems with Applications 36 (2009) 9557-9563.

30. N. Stavropolous, Suppliers in the new economy, Telecommunications Journal of Australia 50 (2000) 2729.

31. T. Ming-Lang, J. H. Chiang, and L. W. Lan, Selection of optimal supplier in supply chain management strategy with analytic network process and choquet integral, Computers \& Industrial Engineering 57 (2009) 330-340.

32. A. H. I. Lee, A fuzzy supplier selection model with the consideration of benefits, opportunities, costs and risks, Expert Systems with Applications 36(2) (2009) 2879-2893.

33. J. Motwani, M. Youssef, Y. Kathawala, and E. Futch, Supplier selection in developing countries: a model development, Integrated Manufacturing Systems 10(3) 154-162.

34. H. Min, International Supplier Selection: A Multiattribute Utility Approach, International Journal of Physical Distribution \& Logistics Management 24(5) (1994) 24-33.

35. S. H. Huang, and H. Keskar, Comprehensive and configurable metrics for supplier selection, International Journal of Production Economics 105(2) (2007) 510523.

36. F. T. S. Chan, N. Kumar, M. K. Tiwari, H. C. W. Lau, and K. L. Choy, Global supplier selection: a fuzzyAHP approach, International Journal of Production Research 46(14) (2008) 3825-3857.

37. Z. Liao and J. Rittscher, A multi-objective supplier selection model under stochastic demand conditions, International Journal of Production Economics 105(1) (2007) 150-159.

38. D. A. Carrera and R. V. Mayorga, Supply chain management: a modular Fuzzy Inference System approach in supplier selection for new product development, Journal of Intelligent Manufacturing 19(1) (2008) 1-12.

39. Z. Liao and J. Rittscher, Integration of supplier selection, procurement lot sizing and carrier selection under dynamic demand conditions 107(2) (2007) 502510 .

40. S. Zaim, M. Sevkli, and M. Tarim, Fuzzy Analytic Hierarchy Based Approach for Supplier Selection, Journal of Euromarketing 12(3) (2003) 147-176.
41. E. -K. Lee, S. Ha, and S. -K. Kim, Supplier selection and management system considering relationships in supply chain management, Engineering Management IEEE Transactions on 48(3) (2001) 307318.

42. D. Wu, Supplier selection in a fuzzy group setting: A method using grey related analysis and DempsterShafer theory, Expert Systems with Applications $\mathbf{3 6}$ (2009) 8892-8899.

43. C. A. Weber, J. R. Current, and W. C. Benton, Vendor selection criteria and methods, European Journal of Operational Research 50 (1991) 2-18.

44. H. T. Lin and W. L. Chang, Order selection and pricing methods using flexible quantity and fuzzy approach for buyer evaluation, European Journal of Operational Research 187 (2008) 415-428.

45. J. Sarkis, G. Nehaman, and J. Priest, A systemic evaluations model for environmentally friendly conscious business practices and strategy, In proceedings of the IEEE International Symposium on Electronics and the Environment, Dallas, Texas, (1996) p. 281-286.

46. P. Humphreys, A. Mccloskey, R. Mcivor, L. Maguire, and C. Glackin, Employing dynamic fuzzy membership functions to assess environmental performance in the supplier selection process, International Journal of Production Research 44(12) (2006) 2379-2419.

47. S. Zanakis, A. Solomon, N. Wishart and S. Dubish, Multi-attribute decision making: A simulation comparison of select methods, European Journal of Operations Research 107 (1998) 507-529.

48. O. Dura'n and J. Aguilo, Computer-aided machinetool selection based on a Fuzzy-AHP approach, Expert Systems with Applications 34 (2008) 1787-1794.

49. E. Herrera-Viedma, F. Chiclana, F. Herrera, and S. Alonso, Group Decision-Making Model with Incomplete Fuzzy Preference Relations Based on Additive Consistency, IEEE Transactions On Systems, Man, And Cybernetics - Part B: Cybernetics 37(1) (2007) 176-189.

50. J. Lu, G. Zhang, and F. Wu, Team Situation Awareness Using Web-based Fuzzy Group Decision Support Systems, International Journal of Computational Intelligence Systems 1(1) (2008) 50-59.

51. X. Li, D. Ruan, J. Liu, and Y. Xu, A LinguisticValued Weighted Aggregation Operator to Multiple Attribute Group Decision Making with Quantative and Qualitative Information, International Journal of Computational Intelligence Systems 1(3) (2008) 274284.

52. G.Wei, X. Zhao, and R. Lin, Some Induced Aggregating Operators with Fuzzy Number Intuitionistic Fuzzy Information and their Applications to Group Decision Making, International Journal of Computational Intelligence Systems 3(1) (2010) 84-95. 
53. T. Entani and M. Inuiguchi,Group Decisions in Interval AHP Based on Interval Regression Analysis, Advances in Soft Computing 68 (2010) 269-280.

54. Y. -M. Wang and K. -S. Chin, A new data envelopment analysis method for priority determination and group decision making in the analytic hierarchy process, European Journal of Operational Research 195(1) (2009) 239-250.

55. Y. Dong, G. Zhang, W.-C. Hong and Y. Xu, Consensus models for AHP group decision making under row geometric mean prioritization method, Decision Support Systems 49(3) (2010) 281-289.

56. U. R. Tuzkaya, and S. Önüt, A fuzzy analytic network process based approach to transportation-model selection between Turkey and Germany: A case study, Information Sciences 178 (2008) 3133-3146.

57. G. Tuzkaya, A. Ozgen, D. Ozgen, and U. R. Tuzkaya, Environmental performance evaluation of suppliers: A hybrid fuzzy multi-criteria decision approach, International Journal of Environmental Science and Technology 6 (2009) 477-490.

58. M. Lockström, J. Schadel, N. Harrison, R. Mose, and $\mathrm{M}$. and $\mathrm{K}$. Malhotra, Antecedents to supplier integration in the automotive, industry: A multiple-case study of foreign subsidiaries in China, Journal of Operations Management 28(3) (2010) 240-256.

59. C. Kahraman, G. Büyüközkan, N. Y. Ateş, A two phase multi-attribute decision-making approach for new product introduction, Information Sciences 177(7) (2007) $1567-1582$.

60. C. Kahraman, S. Çevik, N.Y. Ates, and M. Gülbay, Fuzzy multi-criteria evaluation of industrial robotic systems, Computers \& Industrial Engineering 52(4) (2007) 414-433 